\title{
A study with the electron microscope of the jejunal epithelium in primary malabsorptive disease
}

\author{
D. J. C. SHEARMAN, R. H. GIRDWOOD, A. WYNN WILLIAMS, \\ AND I. W. DELAMORE \\ From the Departments of Medicine and Pathology, University of Edinburgh, and \\ the Gastrointestinal Clinic, Royal Infirmary of Edinburgh
}

SYNOPSIS Jejunal biopsy specimens were obtained by means of the Crosby capsule from a normal person and from seven patients. Of these, three with primary malabsorptive disease (idiopathic steatorrhoea) had an abnormal mucosal pattern under the light microscope, and the microvilli under the electron microscope were stunted, broadened, and sparse. Two with primary malabsorptive disease had normal light microscopic appearances, and the microvilli appeared normal, while two who had appearances typical of primary malabsorptive disease under the light microscope had malignant disease of the small intestine. Of the patients with malignant disease, one had normal microvilli under the electron microscope and the other demonstrated microvilli similar to those found in primary malabsorptive disease. The former patient may have had primary malabsorptive disease in addition to the malignant change but this is uncertain, and there is no reason to believe that this was the case in the latter patient. The changes seen under the light microscope are usually of great value as an aid to diagnosis in primary malabsorptive disease but this is not always the case, and the same applies to electron microscope changes.

With the introduction of simple methods of jejunal biopsy by the oral route, there has recently occurred a significant advance in our knowledge of the appearances of the jejunal mucosa in the condition that is variously known as idiopathic steatorrheoa, adult coeliac disease, gluten-induced enteropathy, and primary malabsorptive disease. Our preference for this last term in the present state of our knowledge is expressed in a recent publication (Girdwood, Delamore, and Wynn Williams, 1961) which also confirms the claims of Shiner (1959) and of Fone, Cooke, Meynell, Brewer, Harris, and Cox (1960) that patients with primary malabsorptive disease may have either a flat mucosal pattern or abnormal blunted villi when the jejunal mucosa is studied by light microscopy. These findings were foreshadowed 46 years earlier by Manson-Bahr's report on the mucosal pattern in tropical sprue (Bahr, 1915).

In our previous paper, reference is made to five patients with primary malabsorptive disease who had a normal jejunal mucosal pattern under the light microscope, and three with an abnormal pattern who proved to have malignant disease of the small intestine.

However, the resolution that can be obtained by light microscopy studies is limited, and reports are now being published of the ultrastructure of the jejunal mucosal cell under the electron microscope.

Over a century ago, the border of the epithelial cell of the intestine was depicted by Henle (1841) as a homogeneous refractile layer. Later, vertical striations were recognized by Baker (1942), and these were thought to provide a pathway for the absorption of nutrients. With the advent of electron microscopy, Granger and Baker (1950) and Dalton, Kahler, Striebich, and Lloyd (1950) were able to show that the striations were closely packed processes which are now called microvilli. Each microvillus consists of an extension of the plasma membrane which encloses cytoplasm continuous with that of the luminal (apical) aspect of the cell. The core of a microvillus is occupied by a dense fibrillar meshwork composed of fine filaments. This meshwork passes into the superficial apical cytoplasm of the cell to merge with a dense feltwork of filaments beneath the striated border, known as the terminal web. Pinocytotic vesicles form at the bases of the intermicrovillous spaces, and are seen towards the free surface of the cell. These vesicles are believed 
to be concerned with the absorption of some nutrients by the cell, and Palay and Karlin (1959b) have observed that fat droplets enter the epithelial cell by pinocytosis at the base of the intermicrovillous space. Fat droplets were not found by these authors within the microvilli, which exhibited no discernible alterations in dimensions or structure during fat absorption. It has been shown by Clark (1959) that until about 18 days after birth the absorptive cells of the small intestine of rats and mice are able to absorb proteins and colloids by pinocytosis. This absorptive mechanism in suckling animals is eliminated by the subcutaneous injection of cortisone acetate.

In relation to the abnormalities of absorption that occur in primary malabsorptive disease it is important to have detailed knowledge of the composition and functions of the normal microvillus. Our information about this is most inadequate, but the striated border (composed of microvilli) has been stained with various histochemical stains and examined under the light microscope. It is reported by Puchtler and Leblond (1958) that the striated border in rats, starved rats, and salamanders gives positive reactions for alkaline phosphatase, carbohydrates, lipids, and proteins but not for nucleic acids. It has been found by Bolt, Pollard, and McCool (1960), using a jejunal biopsy tube, that alkaline phosphatase activity in the brush border is diminished in patients with primary malabsorptive disease.

CHANGES REPORTED IN PRIMARY MALABSORPTIVE DISEASE AND TROPICAL SPRUE

Studies with the electron microscope of the jejunal mucosa in seven cases of tropical sprue and in one case of primary malabsorptive disease have been reported by Hartman, Butterworth, Hartman, Crosby, and Shirai (1960). In four patients with untreated tropical sprue the villi usually bore no intact epithelial covering, and not even a suggestion of microvilli could be found. In the crypts, abnormal epithelial cells were found with microvilli that were sometimes normal in size and number and sometimes short or sparsely distributed or both. Three patients had been treated with folic acid and in them there was some evidence of cellular breakdown, but there was usually an orderly palisade of columnar cells and the microvilli appeared normal. In the patient with primary malabsorptive disease, before treatment and five days after starting a gluten-free diet, the microvilli varied from being abnormally short to being 'extremely stunted'. These authors consider that the absorptive surface in untreated tropical sprue and primary malabsorptive disease is reduced to less than $5 \%$ of normal, loss of epithelium being a factor in the former condition and loss of microvilli in both.

An investigation with the electron microscope was carried out by Zetterqvist and Hendrix (1960) on two patients with primary malabsorptive disease. One was investigated before treatment and four months after beginning a gluten-free diet. The specimens were obtained from the distal duodenum. The other patient had jejunal biopsy done a year after a gluten-free diet had been started. In the first patient the light microscopic pattern before treatment was one of absent villi and infiltration of the lamina propria with inflammatory cells. Under the electron microscope the microvilli were short, asymmetrical, and diminished in number. The cells were otherwise normal. After the gluten-free diet, it is claimed that the microvilli were restored to normal, but it is not clear how many specimens were examined. In the second patient the light microscopic picture was still grossly abnormal after a gluten-free diet had been taken but the microvilli were normal.

Ashworth, Chears, Sanders, and Pearce (1961) claimed that in two cases of primary malabsorptive disease the microvilli were reduced in size and number and that pinocytotic vesicles were decreased in number and the terminal web absent or diminished. One patient had a clinical remission as a result of treatment for four months with a gluten-free diet, but there was no improvement in the histological appearance of the jejunum under the electron microscope.

\section{MATERIAL AND METHODS}

The investigations were carried out on seven patients with primary malabsorptive disease and in one normal person who served as a control. Cases 1, 2, and 3 were typical cases with steatorrhoea of several years' duration, and had evidence of malabsorption by various laboratory tests. Case 3 had been receiving folic acid by mouth for more than six months, but Cases 1 and 2 had not had treatment with folic acid or a gluten-free diet. Further information about Cases 4, 5, 6, and 7 is given below, but, briefly, Cases 4 and 5 had a normal jejunal pattern on light microscopy and Cases 6 and 7 had an abnormal pattern but were found to have malignant disease of the small intestine. Cases 4-7 have been referred to previously (Girdwood et al., 1961).

Jejunal biopsy was carried out with the Crosby intestinal biopsy capsule (Crosby and Kugler, 1957). The time between the taking of the biopsy and fixation ranged from 30 seconds to three minutes. In one instance (Case 7) the biopsy was taken at operation and fixed within 30 seconds of removal.

The mucosa obtained was cut into $1 \mathrm{~mm}$. cubes and fixed in $1 \%$ osmium tetroxide buffered with veronalacetate to $p H \quad 7.2$ (Palade, 1952). The cubes were embedded in an $8: 1$ mixture of butyl and methyl 
methacrylate. Sections, cut with a glass knife on a Servall microtome, were mounted on grids covered with collodion membranes. The electron microscope was an A.E.I., E.M.6, and it was operated at $40 \mathrm{KV}$ with a $50 \mu$ objective aperture.

\section{CLINICAL FEATURES}

The clinical features of the patients with unexpected pathological or histological findings were briefly as follows:-

CASE 4 A 74-year-old woman developed megaloblastic anaemia but had hydrochloric acid in the gastric juice. Her diet was good and she had no diarrhoea. She had not been abroad. She had malabsorption of folic acid, which persisted after treatment with folic acid for six months (output after $5 \mathrm{mg}$. subcutaneously $(\mathrm{A})=$ $3.27 \mathrm{mg}$., output after $5 \mathrm{mg}$. orally $(B)=0.11 \mathrm{mg}$.; excretion index $(B / A \times 100=3.36 \%)$. There was also malabsorption of fat $(8 \cdot 1 \mathrm{~g}$. per day), glucose, xylose, and vitamin $B_{12}(77.1 \%$ of radioactivity in the stools after an $0.5 \mu \mathrm{g}$. dose of ${ }^{58}$ cobalt-labelled cyanocobalamin). A barium follow-through examination showed flocculation of the barium. A jejunal biopsy, done six months after folic acid therapy was started, showed a normal mucosa under the light microscope (Fig. 1). A further biopsy was done after treatment with folic acid had continued for a second period of six months, and the mucosa was again normal under the light microscope. The electron microscope examination was done at this time (Fig. 9).

CASE 5 A 52-year-old man had a six years' history of diarrhoea associated at times with lower abdominal pain. He had not been abroad, and his diet was good. He had been diagnosed as having pernicious anaemia at the age of 30, and was treated thereafter with injections of liver extract. He had malabsorption of fat $(17 \mathrm{~g}$. per day), glucose, and folic acid (A=2.7 mg., $B=1.0 \mathrm{mg}$; excretion index $37.0 \%$ ). He had complete achlorhydria and malabsorption of labelled cyanocobalamin $(90 \%$ of radioactivity in the faeces after an $0.5 \mu \mathrm{g}$. dose). The malabsorption was corrected by an intrinsic factor preparation but not by tetracycline. A barium followthrough examination revealed no abnormality. The patient was thought to have both pernicious anaemia and primary malabsorptive disease. He was treated for three years by his doctor with injections of cyanocobalamin, and then consented to further out-patient investigation. Malabsorption of vitamin $\mathrm{B}_{12}$ was still a feature but absorption of folic acid was then normal. A gastric biopsy showed atrophic gastritis but jejunal biopsy showed a normal mucosa (Fig. 2). Electron microscopy was done at the same time (Fig. 10).

CASE 6 A 50-year-old man was admitted with a six months' history of diarrhoea, weight loss, and abdominal pain. His diet had been normal and he had not been abroad. There was malabsorption of xylose, fat $(7 \cdot 4 \mathrm{~g}$.

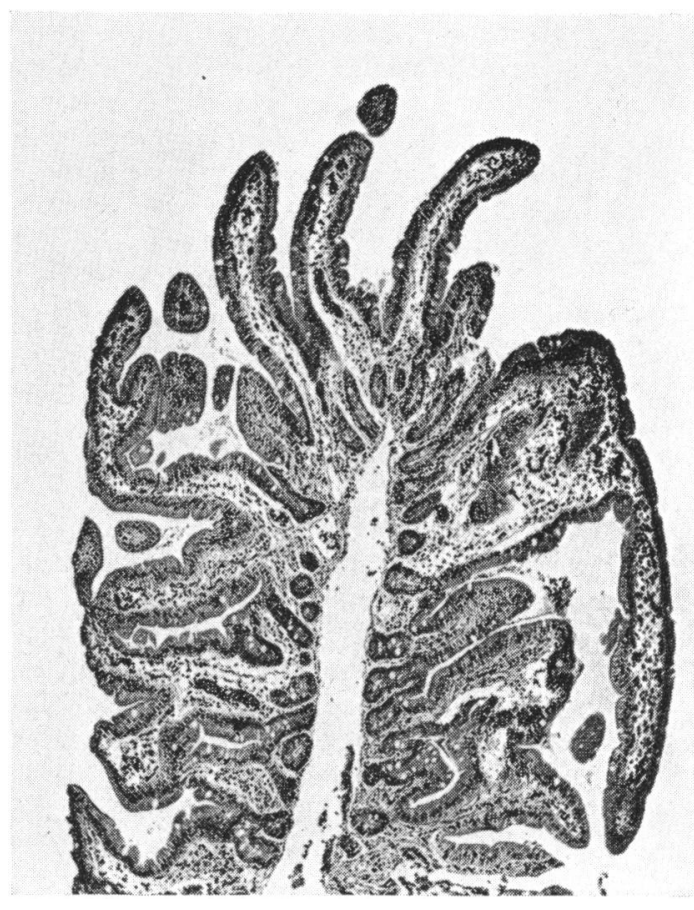

FIG. 1. Biopsy specimen from Case 4 six months after folic acid therapy began. Haematoxylin and eosin $\times 60$.

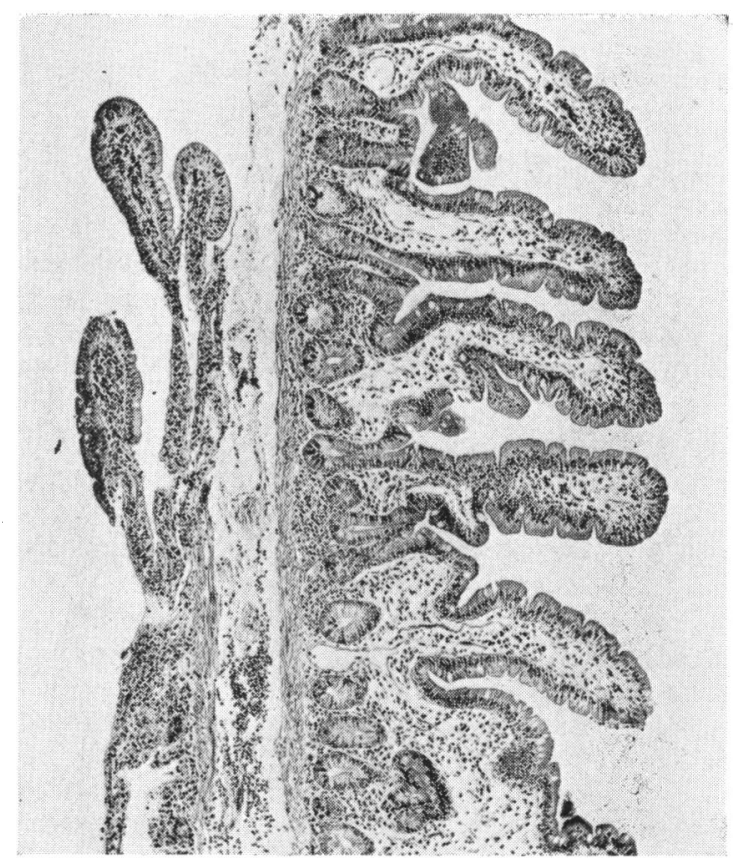

FIG. 2. Biopsy specimen from Case 5. Haematoxylin and $\operatorname{eosin} \times 60$. 


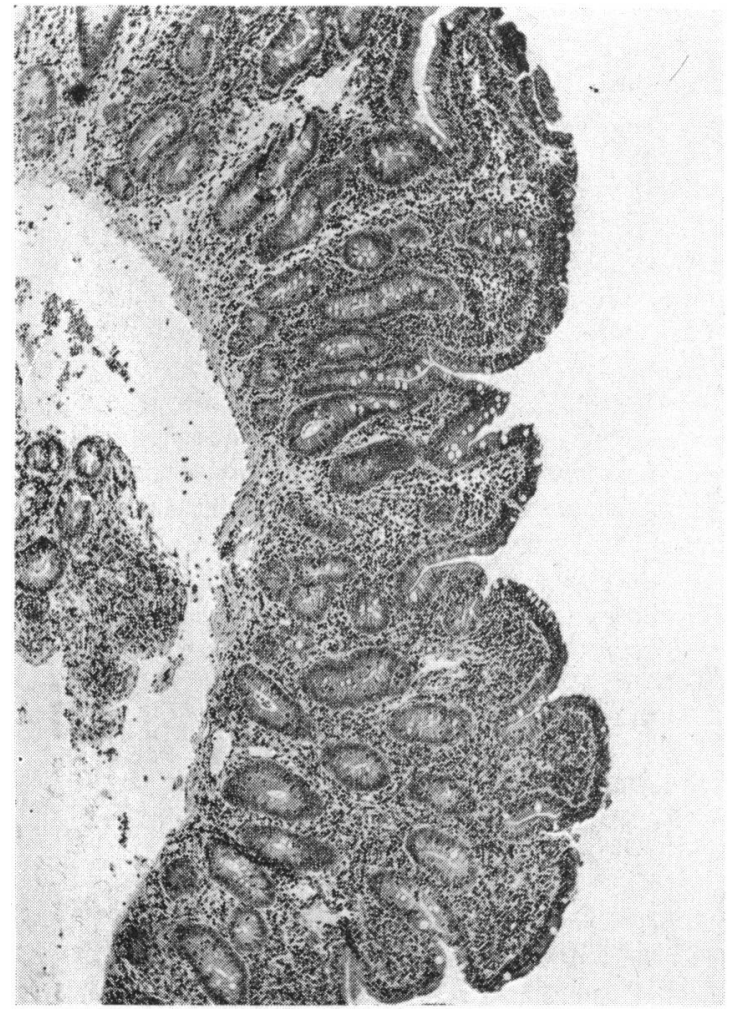

FIG. 3

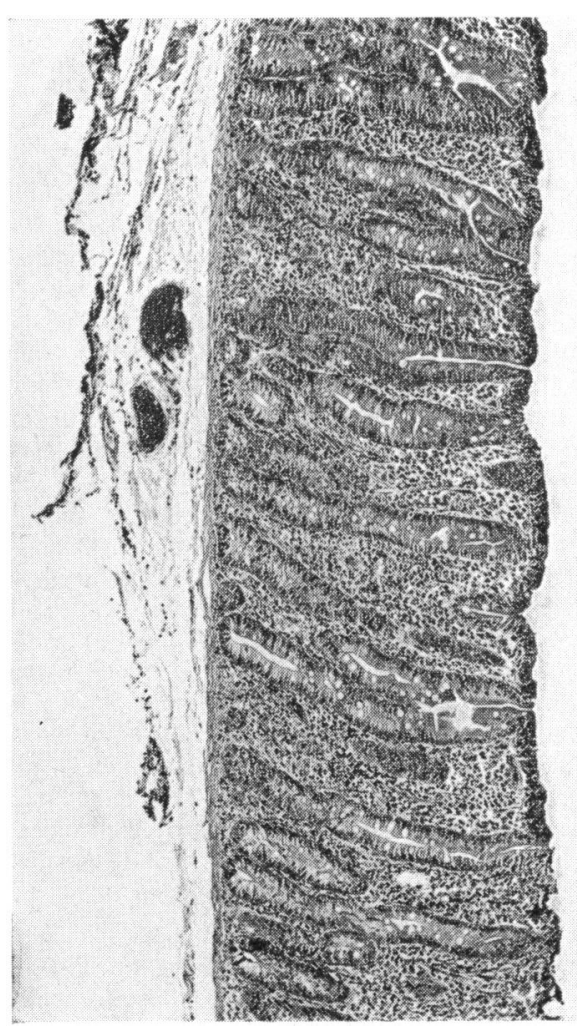

FIG. 4
FIG. 3. Biopsy specimen from Case 6, later found to have reticulum cell sarcoma of the small intestine. Haematoxylin and eosin $\times 60$.

FIG. 4. Biopsy specimen obtained by the oral route from Case 7. Haematoxylin and eosin $\times 60$.

FIG. 5. Biopsy specimen taken at a distance from the area of malignancy during an operation on Case 7 for carcinoma of the jejunum. Haematoxylin and eosin $\times 60$.
FIG. 5

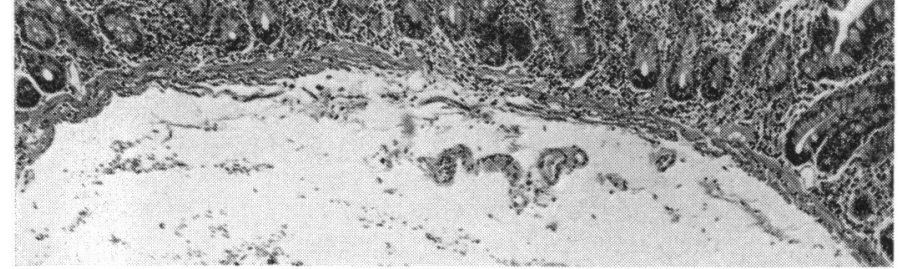


per day) and vitamin $B_{12}$ (less than $1 \%$ of radioactivity in the urine in a Schilling test). The serum vitamin $\mathbf{B}_{\mathbf{1 2}}$ level was at the lower limit of normal $(150 \mu \mu \mathrm{g} . / \mathrm{ml}$. by the $L$. leichmannii method with cyanide). Folic acid absorption was normal. The haemoglobin level was $10.9 \mathrm{~g}$. per $100 \mathrm{ml}$. and the white cell count 15,400 . There was $47 \%$ of eosinophils, and no obvious cause for this. On four occasions, tests of the stool for occult blood were negative and on two occasions positive. A barium meal and follow-through examination showed segmentation and flocculation as in malabsorptive disease, but there was irregularity and dilatation in the duodenum and jejunum. A jejunal biopsy showed the villi to be few in number and shorter and thicker than normal (Fig. 3). Plasma cells were abundant in the stroma. Electron microscopy was also done (Figs. 11 and 12). The patient was treated with a gluten-free diet, and eight weeks later he required a laparotomy because of a suspected perforation of the bowel. He was considered at operation to have Crohn's disease, with perforation of the terminal ileum, and the perforation was closed, no resection or biopsy being done. The patient's condition deteriorated, and he died a month later. He was found to have numerous plaques of ulcerated neoplastic-like tissue throughout the small intestine, particularly in the jejunum. On histological examination these were considered to be areas of reticulum cell sarcoma.

CASE 7 A 50-year-old man had an eight months' history of painless diarrhoea. He had not been abroad and his diet had been good. He was underweight (110 lb.), and had lost $14 \mathrm{lb}$. His height was $5 \mathrm{ft}$. 2 in. He had malabsorption of fat ( $9 \mathrm{~g}$. per day), xylose, glucose, vitamin $B_{12}(2 \cdot 1 \%$ of radioactivity in the urine in a Schilling test), vitamin $K$, iron, and folic acid. There was osteoporosis and the serum level of calcium was low. A barium follow-through examination showed only some dilatation of the jejunum and ileum. The stool did not contain occult blood. The haemoglobin level was $12.5 \mathrm{~g}$. per $100 \mathrm{ml}$., red cells $3,890,000$ per c.mm., but the bone marrow was normal. The E.S.R. was $18 \mathrm{~mm}$./hr. A jejunal biopsy showed a flat mucosal pattern (Fig. 4). The patient was considered to have primary malabsorptive disease, and was treated with folic acid, $5 \mathrm{mg}$. thrice daily orally, calcium gluconate, calciferol, and injections of cyanocobalamin. Five months later he was admitted to another unit with intestinal obstruction, and at operation an anaplastic carcinoma was found, situated about $70 \mathrm{~cm}$. below the duodeno-jejunal flexure. The tumour was about $8 \mathrm{~cm}$. in diameter and mesenteric glands were locally involved. A biopsy specimen taken $20 \mathrm{~cm}$. proximal to the lesion showed broad, stunted villi (Fig. 5), and an electron microscope study was made of the mucosa at this level (Fig. 13).

In view of the extent of the malabsorption it is possible that this patient had primary malabsorptive disease, and that the tumour developed later, but it is not possible to be certain.

\section{RESULTS}

The following observations are based on the electron micrographs of the surfaces of the epithelial cells of the jejunal villi. Micrographs were taken at instrumental magnifications varying from $\times 4,000$ to $\times 10,000$. Microvilli are seen to project from the surface of all epithelial cells. The features of the microvilli are best seen in longitudinal sections and these micrographs are selected for illustration. Pinocytotic vesicles are seen in Figs. 12 and 13. The terminal web of the cell can be seen in most of the micrographs. The luminal parts of the cells are seen to contain only cytoplasm and mitochondria, no nuclei being present because these are situated in the basal parts of the cells. There are no observable variations in the numbers of vesicles within the cytoplasm in any of the micrographs.

MUCOSA OF NORMAL JEJUNUM In longitudinal section the microvilli vary in length from $0.75 \mu$ to $1 \mu$ (Figs. 6 and 7). Those in Fig. 6 represent the longest that were seen on any villus, and those in Fig. 7 the shortest. The microvilli are smooth, straight and regularly spaced.

PRIMARY MALABSORPTIVE DISEASE WITH ABNORMAL MUCOSA In Case 1, the microvilli are short (approximately $0.4 \mu$ in length), fat, and sparse (Fig. 8). In Case 2, the microvilli varied in size from $0 \cdot 1 \mu$ to $0 \cdot 4 \mu$. They were sparse and irregularly spaced. In Case 3, villi were absent from the jejunum. In electron micrographs taken to show part of the surface of epithelial cells on the luminal surface of the jejunum, microvilli were found to be present. They were $0.25 \mu$ to $0.5 \mu$ in length and were sparse and irregularly spaced.

PRIMARY MALABSORPTIVE DISEASE WITH NORMAL MUCOSA In Case 4, occasionally a few short, fat microvilli, measuring less than $0.25 \mu$, are seen (Fig. 9). On many cells, however, the microvilli appeared normal, being spaced regularly and measuring $0.75 \mu$ to $1 \mu$ in length. In Case 5, all the microvilli are in the range of $0.75 \mu$ to $1 \mu$ in length. They are smooth, straight, and regularly spaced (Fig. 10).

MALIGNANT DISEASE OF SMALL INTESTINE WITH ABNORMAL MUCOSA In Case 6, the microvilli vary from $0.25 \mu$ (Fig. 11, near the top of a villus) to $0.5 \mu$ (Fig. 12, the sides of three adjacent villi). It will be seen that there is variation in size and shape not only between cells but even on the surface of the same cell. In Case 7, the microvilli are normal, being straight, regularly spaced, and $0.75 \mu$ in length (Fig. 13). 


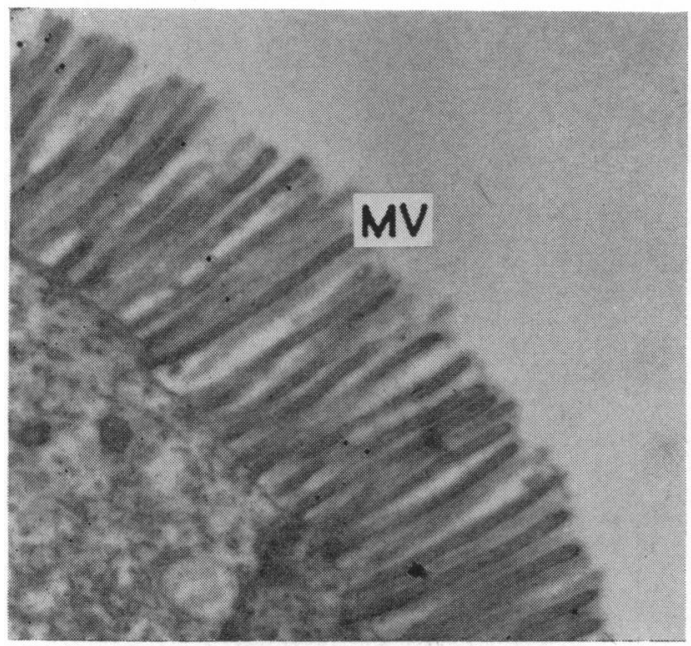

FIG. 6

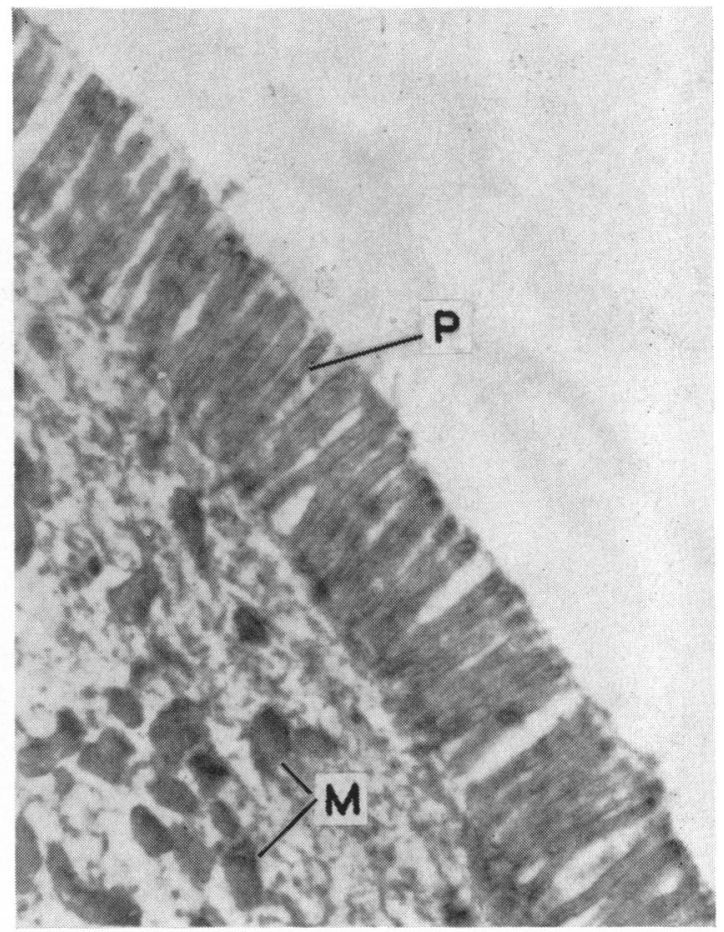

FIG. 7

FIGs. 6 and 7. Surface of normal jejunal epithelial cells showing microvilli.

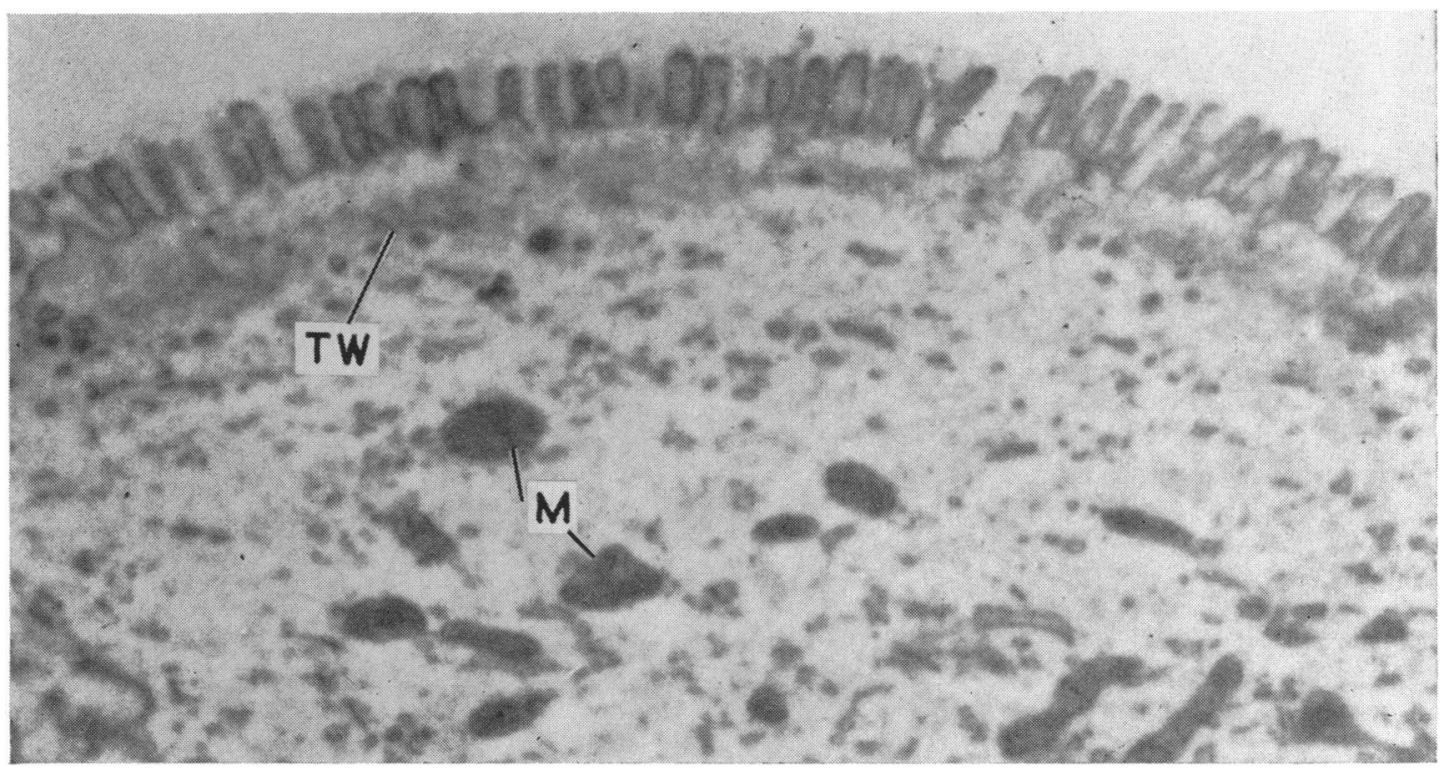

FIG. 8. Surface of jejunal epithelial cell of Case 1 showing abnormal microvilli.

Electron microscope pictures, Figs. $6-13$ are all $\times 20,000 . m v=$ microvilli; $p=$ plasma membrane; $m=$ mitochondria; $t w=$ terminal web; and $v=$ pinocytotic vesicle. 


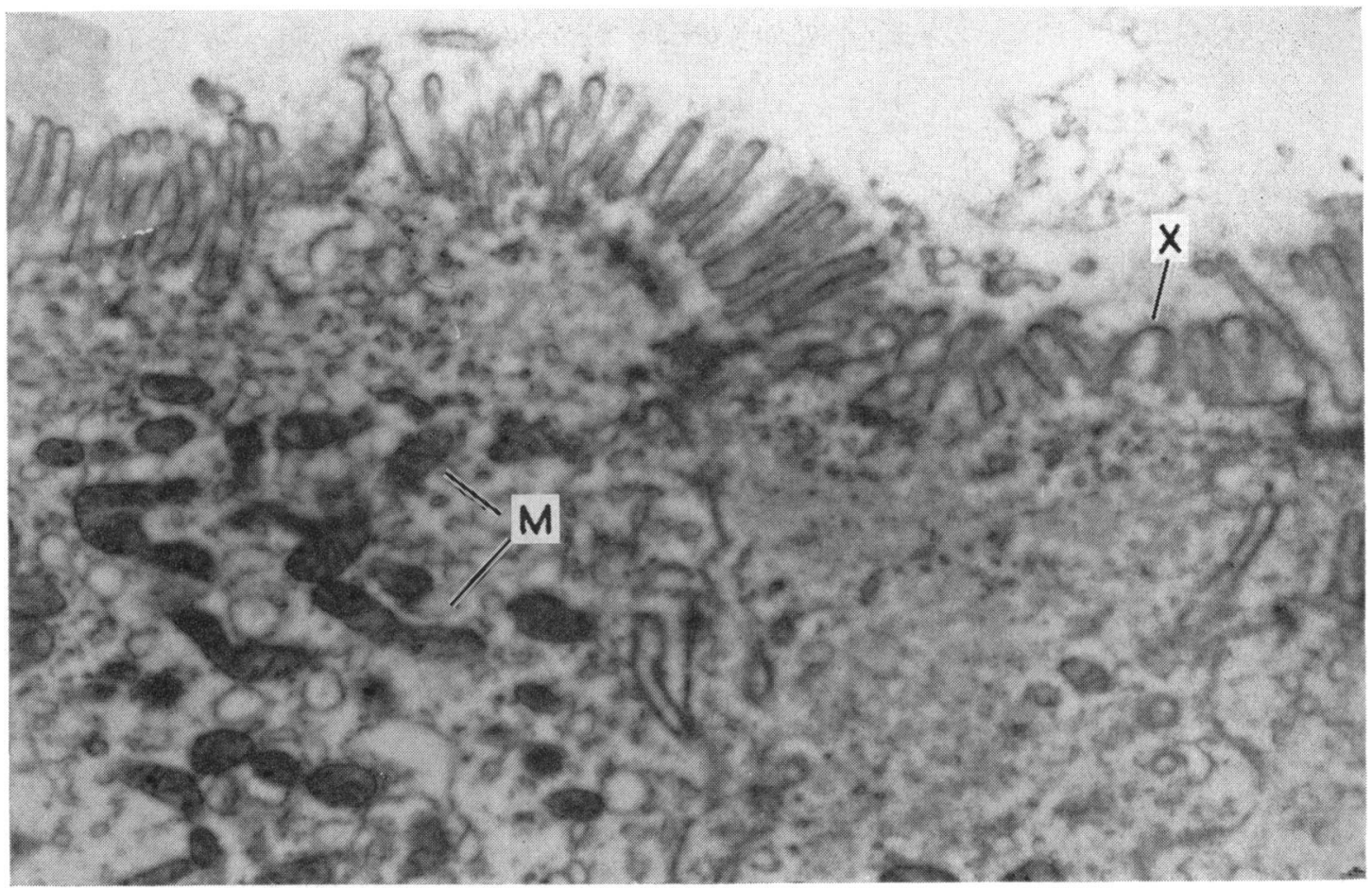

FIG. 9

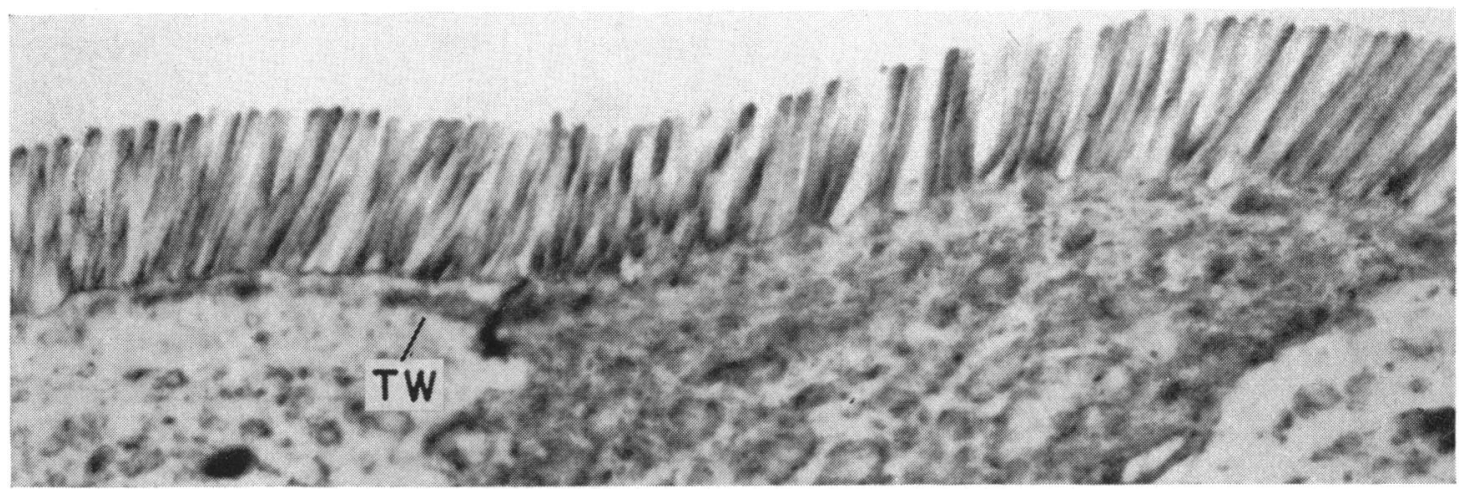

FIG. 10

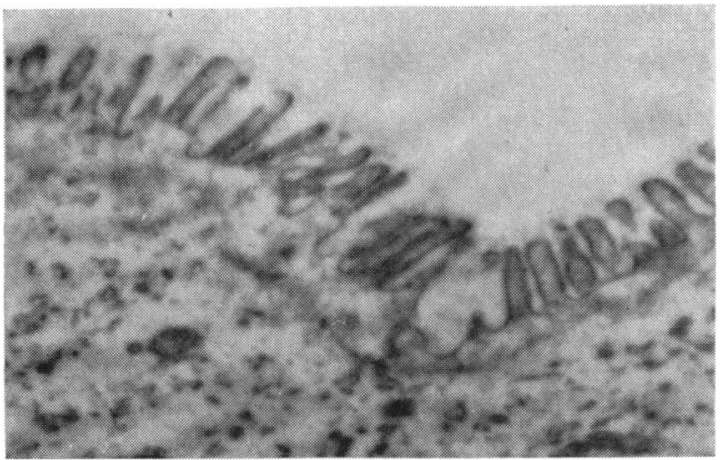

FIG. 9. Surface of jejunal epithelial cells of Case 4 showing normal and abnormal (marked $x$ ) microvilli.

FIG. 10. Surface of jejunal epithelial cells of Case 5 showing normal microvilli.

FIG. 11. Surface of jejunal epithelial cells from Case 6 later found to have reticulum cell sarcoma of the small intestine. The microvilli are abnormal.

FIG. 11 


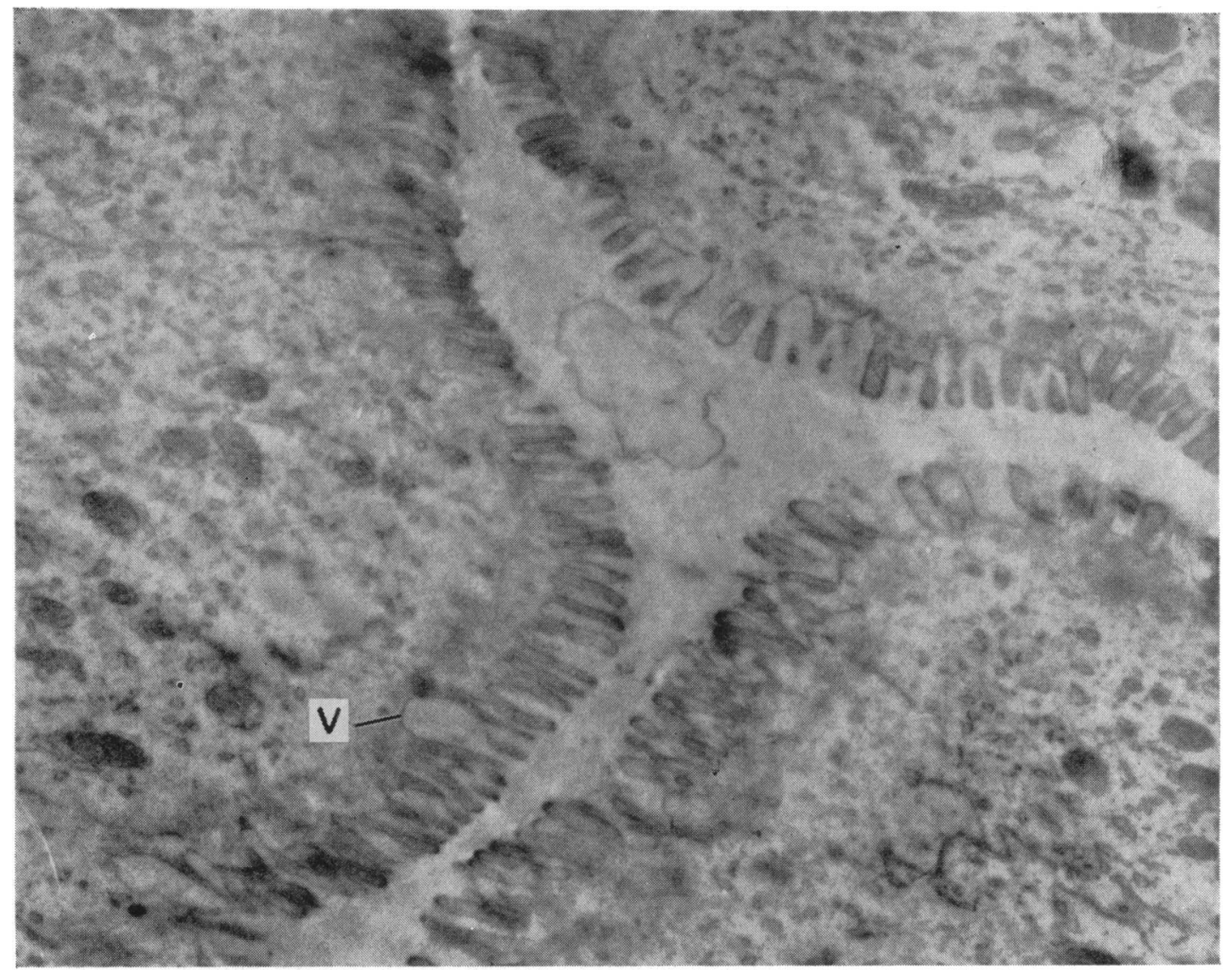

FIG. 12. Surface of jejunal epithelial cells from Case 6 later found to have reticulum cell sarcoma of the small intestine. The microvilli are abnormal.

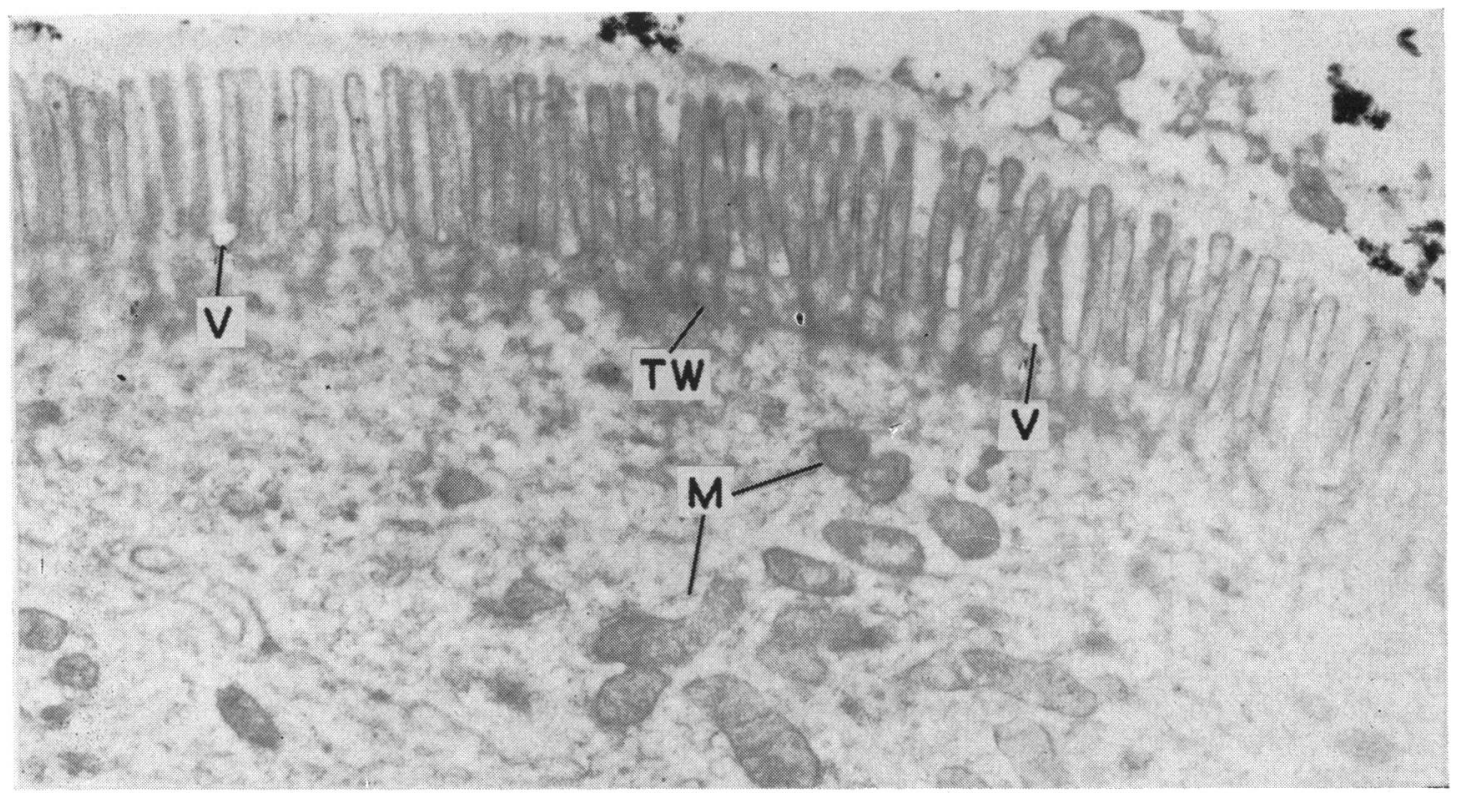

FIG. 13. Surface of jejunal epithelial cells from Case 7 later found to have carcinoma of the jejunum. Although the mucosa was abnormal under the light microscope, the microvilli are normal. 
DISCUSSION

It has been reported by Hartman, Butterworth, Hartman, Crosby, and Shirai (1960) that the lengths of the microvilli in $\mathbf{1 5}$ normal persons varied from $0.8 \mu$ to $1.3 \mu$. Only one normal person's findings are reported here but the lengths of the microvilli are approximately of this magnitude. This, too, has been our finding in other normals. Similar dimensions are found in animals (Palay and Karlin, 1959a), suggesting that this length is optimal.

All biopsy samples were fixed within three minutes of section from the jejunum, and although there is a small amount of vacuolation in the cytoplasm in some instances, there was no evidence of any changes that might have occurred before fixation.

It must be pointed out that one biopsy specimen provides perhaps six cubes of tissue, each with sides about $1 \mathrm{~mm}$. Each cube may have perhaps 10 villi, and some of these are lost in the trimming and sectioning of the cube. Only parts of the remaining villi are examined. Of the total biopsy, at least 100 sections are viewed for electron microscopy, and the photomicrographs are selected to show the characteristic features of these. Other authors have failed to state the extent of their investigations, and this must have an important bearing on the interpretation of results. Within the limits of the present investigation it will be seen that the difference between normal and abnormal microvilli is usually a considerable one. It must be realized that with biopsies fixed at different times there may be slight differences in shrinkage, and that with electron micrographs taken at intervals there is likely to be a slight variation in magnification. However, the difference between the normal and the abnormal is a striking one in our series, and it is not one that can be explained by such variation.

Cases 1, 2, and 3 had primary malabsorptive disease with an abnormal mucosal pattern under the light microscope. Cases 1 and 2 had abnormal villi (category II changes, Girdwood et al., 1961) while Case 3, which had been treated with folic acid, had a flat mucosal surface (category I changes). In all three patients the electron microscope showed microvilli to be present, but to be short $(0 \cdot 1$ to $0.5 \mu)$, sparse, and irregularly spaced.

In the mucosal cells of the two patients with primary malabsorptive disease but a normal mucosal pattern under the light microscope (Cases 4 and 5), the microvilli were normal, except that a few short ones were found in one field in Case 4.

There remain for consideration Cases 6 and 7 which had an abnormal mucosal pattern under the light microscope, and there is every reason to believe that the clinical features and laboratory findings in Case 6 were due to the reticulum cell sarcoma that was affecting the small intestine, and no clinical reason to believe that he had primary malabsorptive disease. In the electron microscope pictures of this patient's mucosal cells, the microvilli were short and broadened, being similar to those found in the patients who undoubtedly had primary malabsorptive disease and demonstrated an abnormal pattern on light microscopy. In Case 7 , on the other hand, it is impossible to know whether or not two diseases were present, namely primary malabsorptive disease and carcinoma of the jejunum. In this instance the electron microscope appearance was normal.

Examination of jejunal biopsy samples with the light microscope is usually a great help as an aid to the diagnosis of primary malabsorptive disease. However, not only is a normal mucosal pattern sometimes seen when this condition is present, but a pattern similar to that occurring in primary malabsorptive disease may be found when the patient has malignant disease of the small intestine. The present studies suggest that, equally, although the microvilli are usually short, broad, and sparse in primary malabsorptive disease, they may be normal, and that abnormal microvilli may be found in the mucosal cells of a patient with malignant disease of the small intestine.

The findings of Palay and Karlin (1959b) suggest that the microvilli are not concerned with the absorption of fat and as yet we are uncertain of their absorptive function. Certainly it would be reasonable to expect that, as they normally increase the free surface of the cell more than twenty-fold (Granger and Baker, 1950; Palay and Karlin, 1959a), the microvilli must be of major importance in relation to some aspect of absorption, and that certain of the abnormalities of absorption in patients with primary malabsorptive disease are related to this loss of free surface. If this is so, the patient with primary malabsorptive disease or with tropical sprue is gravely deficient in absorbing surface because to the handicap of a paucity of villi there is added this further decrease in the surface area of individual cells. Perhaps in the not so distant future we shall have further information as to which abnormality of absorption is due to loss of villous surface and which to reduction of the surface presented by microvilli.

We are grateful to Dr. A. R. Muir, of the Department of Anatomy, University of Edinburgh, for his advice. The electron microscope, which is on permanent loan from the Wellcome Foundation, was maintained by Mr. G. Wilson. Financial assistance was provided by a grant 
from the Medical Research Council. One of us (D.J.C.S.) was in receipt of a Gunning medical bursary from the University of Edinburgh for undergraduate research, and A.W.W. received a grant from the Secretary of State for Scotland.

We wish to thank Sir Derrick Dunlop for permission to investigate Case 6 which was under his care, and also Professors M. F. A. Woodruff and John Brace who performed the operations on Cases 6 and 7 respectively.

\section{REFERENCES}

Ashworth, C. T., Chears, W. C., Sanders, E., and Pearce, M. B. (1961). Arch. Path. (Chicago), 71, 13.

Bahr, P. H. (1915). A Report on Researches on Sprue in Ceylon, 1912-1914. University Press, Cambridge.

Baker, J. R. (1942). Quart. J. micr. Sci., 84, 73 .

Bolt, R. J., Pollard, H. M., and McCool, S. (1960). Amer. J. clin. Path., 34, 43.
Clark, S. J. Jr. (1959). J. biophys. biochem. Cytol., 5, 41.

Crosby, W. H., and Kugler, H. W. (1957). Amer. J. dig. Dis., n.s. $2,236$.

Dalton, A. J., Kahler, H., Striebich, M. J., and Lloyd, B. (1950). J. nat. Cancer Inst., 11, 439.

Fone, D. J., Cooke, W. T., Meynell, M. J., Brewer, D. B., Harris, E. L., and Cox, E. V. (1960). Lancet, 1, 933.

Girdwood, R. H., Delamore, I. W., and Wynn Williams, A. (1961). Brit. med. J., 1, 319.

Granger, B., and Baker, R. F. (1950). Anat. Rec., 107, 423.

Hartman, R. S., Butterworth, C. E., Hartman, R. E., Crosby, W. H., and Shirai, A. (1960). Gastroenterology, 38, 506.

Henle, J. (1841). Allgemeine Anatomie, Voss, Leipzig. Cited by Gegenbaur in W. von Möllendorff (1927) Handbuch der mikroskopische Anatomie des Menschen. Vol. 2. Springer, Berlin.

Palade, G. E. (1952). J. exp. Med., 95, 285.

Palay, S. L., and Karlin, L. J. (1959a). J. biophys. biochem. Cytol., 5, 363 .

- (1959b). Ibid., 5, 373.

Puchtler, H., and Leblond, C. P. (1958). Amer. J. Anat., 102, 1.

Shiner, M. (1959). Proc. roy. Soc. Med., 52, 10.

Zetterqvist, H., and Hendrix, T. R. (1960). Bull. Johns Hopk. Hosp., 106, 240. 